me about the middle of December. Since then I have used it so frequently and with such perfect satisfaction, both for the examination of the post-nasal cavity and for various operations therein, such as removal of adenoid tissue, snaring lower turbinated hypertrophies and galvano-cauterizations, that I now consider it an invaluable addition to the rhinologist's armamentarium. For a long time back I had used to draw the palate forward, for examination, a simple loop of silver wire, with a short rubber band which caught between the teeth when practicable, or with two long rubber loops which hooked over the ears, as less uncomfortable than passing a piece of rubber tubing through the nostrils out of the mouth, and tying it over the upper lip.

The latter method I always nsed for operations, as more reliable and less likely to become displaced than the former. The present instrument, however, does away with both methods, and is infinitely preferable to either.

It is made of a square steel bar about $3 \mathrm{~mm}$. thick, terminating in a loop of pure silver wire heavy enough to hold the palate and light enough to be readily changed in shape by the fingers to suit each individual case, being made smaller for children and larger for a more capacious pharynx. On the bar slides the attachment which clamps over the upper lip and holds the retractor in position. This sliding attachment, with two arms, requires no fixation to keep it in position, the tension being alone sufficient to make it immoveable on the square bar. For greater security, however, in performing an operation, a small fixation screw is attached to the side of the slide to fasten it securely, so that facial eontortions must not displace it.

As shown in the plates, I had two attachments made at first, one with two steel wire arms terminating in silver wire loops, the ends of which caught in the nostrils, or on either side of the alæ of the nose, and another attachment terminating in two hard rubber buttons, which caught in the depressions over the alveolar processes on the same principle as a similar instrument described in the Medical Record, of Jan, I4, I88 ז, by Dr. Porcher, of Charleston.

The reason of the two attachments was that I found in some cases one suited, and in others the second attachment was preferable. Since the plates were made about January I, I find the one with silver loops answers both purposes, as it can be moulded by the fingers to suit any case, just as the terminal loop of the bar which catches the palate.

There is but one objection to urge against the instrument, and that is, that the bar may get in the way of operating in the right nostril, but this does not hold good if the operator is ambidextrous, and moreover, it is so small that it is not much of an obstruction. It is applied and moved so rapidly that it can be taken away repeatedly in performing operation to rest the patient or the surgeon. My experience already has demonstrated its great advantages over any known method for working in the post-nasal cavity, and I am satisfied any of my confrères who give it a trial will agree with me.

\section{A NEW ATOMIZER FOR OFFICE USE.}

BY E. FLETCHER INGALS, AM., M.D., PROFESSOR OF LARYNGOLOGY, RUSH MEDICAL COLLEGB, ETC., CHICAGO.

I wish to call the attention of the profession to a new atomizer for office use, that has been made at my request by the Davidson Rubber Company. It is known as "Davidson's Combination, No. 66," by which name it can be procured through any of the instrument dealers in this city.

All atomizers, thus far, have been more or less defective, but the one shown in the cut comes nearer to perfection than any other I have seen.

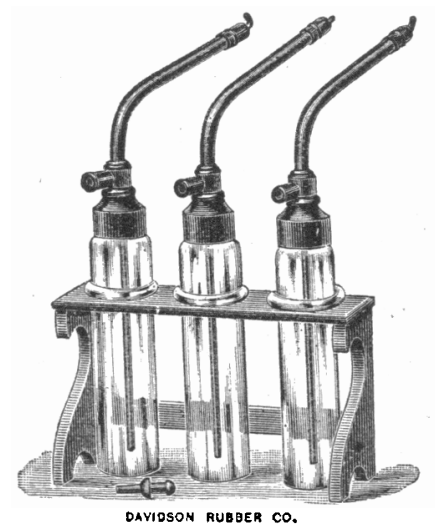

The spray-tube is made of hard rubber and consists of two parts, an inner and an outer tube. The inner tube through which the fluid rises, extends from the bottom of the bottle containing the medicated liquid, to the end of the spray-tube, where it is capped by a smaller movable tip. The outer tube, which conveys the blast of air, extends from the top of the bottle, to which it is firmly fixed by a screw thread, to the end of the instrument, where it is capped by a removable tip. There are three different tips for each outer tube, which enables the physician to throw a spray either horizontally, at a right or oblique angle, up, down or laterally. One of these tips is half an inch in length, which renders it peculiarly serviceable for throwing spray into the naso-pharynx, a place that it is impossible to reach in a majority of cases with the short tips furnished with other instruments. As the tips of both the outer and inner tubes can be easily removed, the tubes may be readily cleansed if they become stopped. By removing the tip from the inner tube, and screwing down firmly the tip on the outer tube, this instrument will throw freely fluid cosmoline or oil, even with a low pressure, or by the hand ball.

Each of these atomizers is so constructed that it fits accurately upon the air cut off, manufactured by the same firm, and with each set is an extra attachment which enables either of the instruments to be used with the ordinary rubber hand bulb.

These instruments are put up, three in a set, in a neat little rack, and as each has three tips, the set is equivalent to nine spray tubes of the ordinary apparatus.

The tubes being made of rubber, anything which 
a physician is likely to employ as a spray may be used through them without injury, excepting iodine. All metallic spray-tubes, (excepting very expensive platinum) corrode with various solutions, and are therefore soon ruined. Glass tubes are more bulky than these, are more difficult to clean, and are sub. ject to a great deal of breakage, which renders them expensive, while at the same time three of them are required to answer even a part of the purpose of one of these.

The spray tube itself, in these instruments, is not new, it being the same as that in Davidson's No. 59, old style, hand atomizer, which, by the way, is now the best instrument in the market for the patient's use, if one is careful to order the screw top and long tip. One of these tubes I have had in almost constant use for many years, and it is still good.

I have brought this matter before the profession because I believe that we now have a much more reliable instrument than ever before, and I believe a single set of this kind would be found very valuable even to many general practitioners.

For the complete outfit of a laryngologist's office nothing can surpass in utility a suitable number of these instruments, arranged in a convenient rack.

No. 7o State Street.

\section{FOREIGN CORRESPONDENCE}

\section{LETTER FROM PARIS.}

(FROM OUR OWN CORRESPONDENT.)

The Muscular Force of Epileptics-Nature and Treatment of Granular Conjunctivitis-Antiseptic Treatment of Diphtheria-Ireatment of Burns.

At the last meeting of the Sociéte de Biologie, Dr. Féré read a note on the muscular force of epileptic subjects. From observations of several epileptics in his hospital ward, he ascertained that the muscular force of these patients, measured by the dynamometer, was less by one-fourth or one-third that of healthy individuals. This is contrary to the generally received opinion. The author then wished to ascertain the modifications these muscular forces underwent in the different manifestations of the disease. Dr. Féré noticed that frequently the "aura" coincided with a diminution of the muscular force, and that the same was the case after the fit, whether the latter was complete or incomplete, as well as after simple vertigo. $\mathrm{He}$ also noticed that this diminution was generally predominant in one of the sides of the body, and it was precisely in that side where the convulsions predominated. This fact is not to be wondered at, and it confirms the theory of Hughlings Jackson, who claims that the period of stertor consecutive to the fit is comparable to an attack of apoplexy with hemiplegia. Dr. Féré moreover noticed that the diminution of the muscrlar force was more marked after the nocturnal than after the diurnal attacks.

In his thesis for the doctorate, M. Desormes chose for his subject the nature and treatment of granular conjunctivitis. Starting from the principle of the contagiousness of granular conjunctivitis, which had been demonstrated by Sattler and other observers to be due to the presence of a specific microbe, the author advises the application of local and at the same time general treatment. The former is to be directed against the infecting agent, whilst the latter should have for its object the placing the organism in a state to resist this agent. As long as the granulations have not reached the period of organization, the author employs the glycerate of the sulphate of $C$ copper in the proportion of $I$ to 8 parts. When once the cicatricial tissue is formed, the microbe becomes surrounded by a sort of fibrous shell which protects it against the action of the drug. In these cases, after having rendered the conjunctiva insensible with cocaine, the granulations must be lightly touched with the point of a small camel's-hair brush dipped in a solution, very concentrated, of chromic acid. The next day the small scar which had been formed will be found detached, and one is then able to cauterize the eyelids with the glycerate of the sulphate of copper which, in this manner, is put in contact with the microbe. Five or six cauterizations with the chromic acid suffice to obtain a notable improvement. The cauterizations should be practiced every four or five days. At the same time the organism should be supported by means of appropriate remedies and substantial food. Elevated positions are very favorable to the cure, as it has been observed that conjunctival granulations do not develop. beyond a certain height.

In the Archives de Laryngologie, Dr. Legendre, writing on the antiseptic treatment of diphtheria, states that after having examined the different antiseptic remedies imagined against this malady, the author brings prominently to notice the energetic procedure adopted by Dr. Soulez, of Romorantin, and which has been applied by Dr. Gaucher, physician to the hospitals of Paris. The principle of the treatment is to concentrate all the efforts of the physician in the destruction of the false membranes and the antiseptic cauterization of the subjacent mucous membrane. The treatment consists in the application with a rather stiff brush impregnated with a saturated solution of carbolic acid and camphor in alcohol, but before applying the brush the superfluous liquid should be pressed out so as to prevent any of it falling into the larynx. The brush is then vigorously applied to all the parts of the throat which are covered with false membranes, and in such a manner that as much of the latter may be mechanically removed as may be possible. The application should be made three or four times in quick succession, without being deterred by the terrible sufferings caused by the operation. This should be done twice daily until the false membranes have ceased to be reproduced. In the intervals frequent irrigations with a solution of carbolic acid of I per cent. should be practiced. The absolute condition of the success of the treatment appears to be in the energy with which the cauterization is practiced. One must not only remove by rubbing the pseudo-membranous layers, but the denuded mucous membrane must be 